\title{
Inhibitory effects of tilianin on the expression of inducible nitric oxide synthase in low density lipoprotein receptor deficiency mice
}

\author{
Ki-Hoan $\mathrm{Nam}^{3}$, Jae-Hoon Choi ${ }^{1}$, \\ Yun-Jeong Seo ${ }^{1}$, Young-Mi Lee ${ }^{1}$, \\ Yong-Sung Won ${ }^{4}$, Mi-Ran Lee ${ }^{1}$, \\ Mi-Ni Lee ${ }^{1}$, Jong-Gil Park', \\ Young-Myeong $\mathrm{Kim}^{2}$, Hyoung-Chin $\mathrm{Kim}^{3}$, \\ Chul-Ho Lee ${ }^{3}$, Hyeong-Kyu Lee ${ }^{3}$, \\ Sei-Ryang $\mathrm{Oh}^{3}$ and Goo Taeg $\mathrm{Oh}^{1,5}$ \\ ${ }^{1}$ Division of Molecular Life Sciences and \\ Center for Cell Signaling Research \\ Ewha Womans University \\ Seoul 120-750, Korea \\ ${ }^{2}$ Vascular System Research Center \\ Kangwon National University \\ Chuncheon 200-701, Korea \\ ${ }^{3}$ Korea Research Institute of Bioscience and Biotechnology \\ Daejeon 305-333, Korea \\ ${ }^{4}$ Department of Surgery \\ St. Vincent's Hospital \\ The Catholic University of Korea \\ Suwon 442-723, Korea \\ ${ }^{5}$ Corresponding author: Tel, 82-2-3277-4128; \\ Fax, 82-2-3277-3760; E-mail, gootaeg@ewha.ac.kr
}

Accepted 24 July 2006

Abbreviations: HUVEC, human umbilical endothelial cell; Ldlr, low density lipoprotein receptor; NO, nitric oxide; NOS, nitric oxide synthase; VCAM-1, vascular cell adhesion molecule-1

\begin{abstract}
We investigated the effect of tilianin upon inducible nitric oxide synthesis in the plasma of low-density lipoprotein receptor knock-out (LdIr-/-) mice fed with high cholesterol diet and in primary peritoneal macrophages of LdIr-/- mice. High cholesterol diet induced nitric oxide production in the plasma of LdIr-/- mice. Tilianin reduced the level of nitric oxide (NO) in plasma from LdIr-/- mice induced by the high cholesterol diet. Tilianin also inhibited the NO production from the primary culture of peritoneal macrophages treated with lipopolysaccharide. The inhibition of NO production was caused by the suppression of inducible nitric oxide synthase (iNOS) gene expression in peritoneal macrophages isolated from LdIr-/- mice. Moreover, tilianin inhibited the
\end{abstract}

transcriptional activation of iNOS promoter that has NF- $\mathrm{kB}$ binding element. Thus, these results provide the first evidence that tilianin inhibit iNOS expression and production of NO and may act as a potential anti-inflammatory agent.

Keywords: anti-inflammatory agents; hyperlipoproteinemia; nitric oxide synthase type II; nitric oxide; tilianin

\section{Introduction}

$\mathrm{NO}$ is a gaseous free radical with very short half-life in biological system and can act both as a weak oxidant and as a reductant (Kanner et al., 1991). NO is synthesized in mammals by the nitric oxide synthases (NOS). There are three NOS isoforms: endothelial NOS (eNOS), neuronal NOS (nNOS), and inducible NOS (iNOS). Unlike eNOS and nNOS, iNOS is not constitutively expressed in macrophages and smooth muscle cells of inflammatory vascular tissues. In human atherosclerotic lesions, however, all three isoforms can be demonstrated (Wilcox et al., 1997). Especially, iNOS expression has been localized to vascular smooth muscle cells and mononuclear leukocytes in early and advanced atherosclerosis (Esaki et al., 1997).

Murine iNOS expression has been observed in various types of cells, including macrophages (Hibbs et al., 1988), endothelial cells (Gross et al., 1991), smooth muscle cells (Beasley et al., 1991), and cardiac myocytes (Schulz et al., 1992). In human patients with infectious or inflammatory disease, iNOS is most readily observed in monocytes or macrophages (MacMicking et al., 1997). Therefore, in contrast to low level of NO produced by eNOS (Wever et al., 1998), excessive NO prouction by iNOS in macrophages is considered to be proatherogenic (Buttery et al., 1996; MacMicking et al., 1997). NO interacts with superoxide to form the strong oxidant peroxynitrite (ONOO-) (Beckman et al., 1990), which induces lipid peroxidation and nitrosylation of tyrosine residue in human atherosclerotic lesions (Beckmann et al., 1994; Wilcox et al., 1997). In addition, it has been shown that suppression of NO by NOS inhibitor or iNOS gene deficiency (iNOS-/-) resulted in reduced atherosclerosis (Behr-Roussel et al., 2000; Detmers et al., 2000). Thus excessive NO has the potential to exacerbate 
atherosclerosis.

In our previous study, we have reported that tilianin, a major component of Agastache rugosa (Labiatae) significantly inhibits the tumor necrotic factor- $\alpha$ (TNF- $\alpha$ )-induced expression of vascular cell adhesion molecule-1 (VCAM-1) in human umbilical vein endothelial cells (HUVEC) as its potential antiatherogenic mechanism (Hong et al., 2001; Nam et al., 2005). However, it has not been determined the effect of tilianin on NO production. Here we report that tilianin potently inhibited NO production by iNOS, another possible anti-atherogenic mechanism. We have demonstrated the inhibitory effects in in vivo as well as in vitro.

\section{Materials and Methods}

\section{Animal model}

All animal experiments were approved by Institutional Animal Care and Use Committees (IACUC) of Ewha Womans University and followed National Research Council Guidelines. Twenty-five low density lipoprotein receptor-null ( $L d l r-/-)$ male mice were divided into three groups (normal diet fed, $n=5$, high-cholesterol diet (HCD) only; $n=10, \mathrm{HCD}$ supplemented with tilianin; $n=10)$. The HCD contained $1.25 \%$ cholesterol, $6 \%$ fat and $0.5 \%$ cholic acid (CRF-1, Oriental Yeast Co., Ltd., Chiba, Japan). Tilianin was supplemented with $0.1 \%$ (wt/wt) of HCD. After 8 week experiment, plasma from the mice were collected and subjected to the measurement of total nitric oxide.

\section{Histological finding and measurement of fatty streak lesion}

The frozen sections of the aortic sinus were reacted with a rabbit anti-mouse iNOS antibody (Santa Cruz Biotechnology, CA) and a rabbit anti-nitrotyrosine antibody (Upstate Biotechnology, NY) at 1:200 dilutions, then the reactivities were detected using ABC kit (Vector Laboratory, CA). Fatty streak lesions were quantified by evaluating the lesion size in the aortic sinus, as previously described (Paigen et al., 1987). All hearts were sectioned using a cryostat at $-20^{\circ} \mathrm{C}$ and six consecutive $9 \mu \mathrm{m}$-thick sections were cut from the aorta where the valve cusp becomes visible. Atherosclerotic plaque was stained with Oil red $\mathrm{O}$ and counter-stained with Harris hematoxylin. The lesion area was then quantified by computer-assisted morphometry (Image pro plus, MD) and the average lesion size was calculated for each animal.

\section{Determination of NO synthesis}

Nitric oxide (NO) production was measured by monitoring levels of nitrite plus nitrate $\left(\mathrm{NO}_{\mathrm{x}}\right)$ in plasma using automatic NO analyzer described previously (Morita et al., 1994). Nitrite in culture media was measured spectrophotometrically as described (Sherman et al., 1993) using the Griess reagent.

\section{Culture of peritoneal macrophages}

Mice were injected with $2 \mathrm{ml}$ of $4 \%$ thioglycolate broth. After 6 days, peritoneal macrophages were isolated from peritoneal lavage of mice. Peritoneal macrophages were cultured in Dulbecco's modified eagle medium (DMEM) supplemented with $10 \%$ fetal bovine serum, $2 \mathrm{mM}$ L-glutamine, penicillin (100 $\mathrm{U} / \mathrm{ml})$, and streptomycin $(100 \mu \mathrm{g} / \mathrm{ml})$.

\section{Immunoblot analysis}

The isolated peritoneal macrophages were incubated with tilianin $(1,10,100 \mu \mathrm{M})$ for $2 \mathrm{~h}$ and immediately activated by LPS $(2 \mu \mathrm{g} / \mathrm{ml})$ at $37^{\circ} \mathrm{C}$ for $18 \mathrm{~h}$. The macrophages were harvested, washed with PBS containing $0.1 \mathrm{mM}$ PMSF, and lysed by three cycles of freezing and thawing in liquid nitrogen. Cytosolic fraction was obtained by centrifugation at $12,000 \mathrm{~g}$ at $4^{\circ} \mathrm{C}$ for $10 \mathrm{~min}$. The concentration of protein was analyzed by the Lowery method. Samples $(50 \mu \mathrm{g})$ were separated on $8 \%$ SDS-PAGE and transferred to nitrocellulose membrane (Schleicher \& Schuell, Keene, NY). The detection of iNOS was performed with anti-iNOS antibody (Santa Cruz Biotechnology, CA) and ECL western blotting analysis system (Amersham, UK).

\section{Analysis of iNOS mRNA}

The expressions of iNOS was determined by semiquantitative RT-PCR, using $\beta$-actin as an internal control. Primary peritoneal macrophages $\left(6 \times 10^{6}\right.$ cells per $100 \mathrm{~mm}$ culture dish) were pre-treated with tilianin $(1,10$, and $100 \mu \mathrm{M})$ for $2 \mathrm{~h}$, and stimulated with LPS $(2 \mu \mathrm{g} / \mathrm{ml})$ for $18 \mathrm{~h}$. Total RNA was extracted from the macrophages using a TRIZOL (Gibco BRL, $M D)$ reagent. The forward primer for mouse iNOS (1) 5'-CTG CAG CAC TTG GAT CAG GAA CCT G-3', and the reverse primer (2) 5'- GGG AGT AGC CTG TGT GCA CCT GGA A -3' define an amplicon of $311 \mathrm{bp}$. The forward primer for $\beta$-actin (1) 5'-TGG AAT CCT GTG GCA TCC ATG AAA C-3', and the reverse primer (2) 5'-TAA AAC GCA GCT CAG TAA CAG TCC G-3' define an amplicon of $349 \mathrm{bp}$. The densitometric analysis was performed with Image Analysis Software (Bio 1D Version 99, Vilber Lour- 
mat, France) to determine the relative band density. The internal control was used to avoid saturation of PCR product.

\section{Transient transfection assay}

A spontaneously transfected mouse monocyte/macrophage cell (RAW264.7) was used because of their high transfection efficiency. Cells were plated in 6 -well plates at $5 \times 10^{5}$ cells/well in DMEM (Gibco BRL, MD) containing $10 \%$ fetal calf serum. After growing at $37^{\circ} \mathrm{C}$ for $20 \mathrm{~h}, 3 \mu \mathrm{g}$ of piNOS-Luc plasmids containing iNOS promoter $(-1,029 \sim+159)$ (Lowenstein et al., 1993) and luciferase reporter were transfected using FuGENE6 (Roche, Mannheim, Germany) according to the manufacturer's direc-

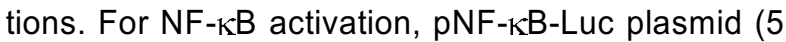
$\times N F-\kappa B$; Stratagene, $C A$ ) was transfected to RAW264.7 cells. The control plasmid pCMVb $(1 \mu \mathrm{g})$
(Clontech, CA) was co-transfected to monitor the transfection efficiency. After $20 \mathrm{~h}$ of transfection, medium was changed and tilianin $(1,10$, and 100 $\mu \mathrm{M})$ was pretreated for $2 \mathrm{~h}$ before LPS $(200 \mathrm{ng} / \mathrm{ml})$ treatment. After additional $48 \mathrm{~h}$ cultures, cells were then harvested and luciferase activities were determined using the Dual Luciferase assay (Promega, $\mathrm{WI})$. The luciferase activity was normalized for transfection efficiency after determining the $\beta$-galactosidase activity of the same sample. Each transfection was carried out in triplicate and experiments were repeated at least four times.

\section{Electrophoretic mobility shift assay}

Nuclear extracts were prepared from cells by lysing them in buffer A [10 mM HEPES ( $\mathrm{pH} 7.5), 1.5 \mathrm{mM}$ $\mathrm{MgCl}_{2}, 10 \mathrm{mM} \mathrm{KCl}$, and $0.1 \%$ Nonidet P-40]. Subsequently, the solution was centrifuged to pellet the
A
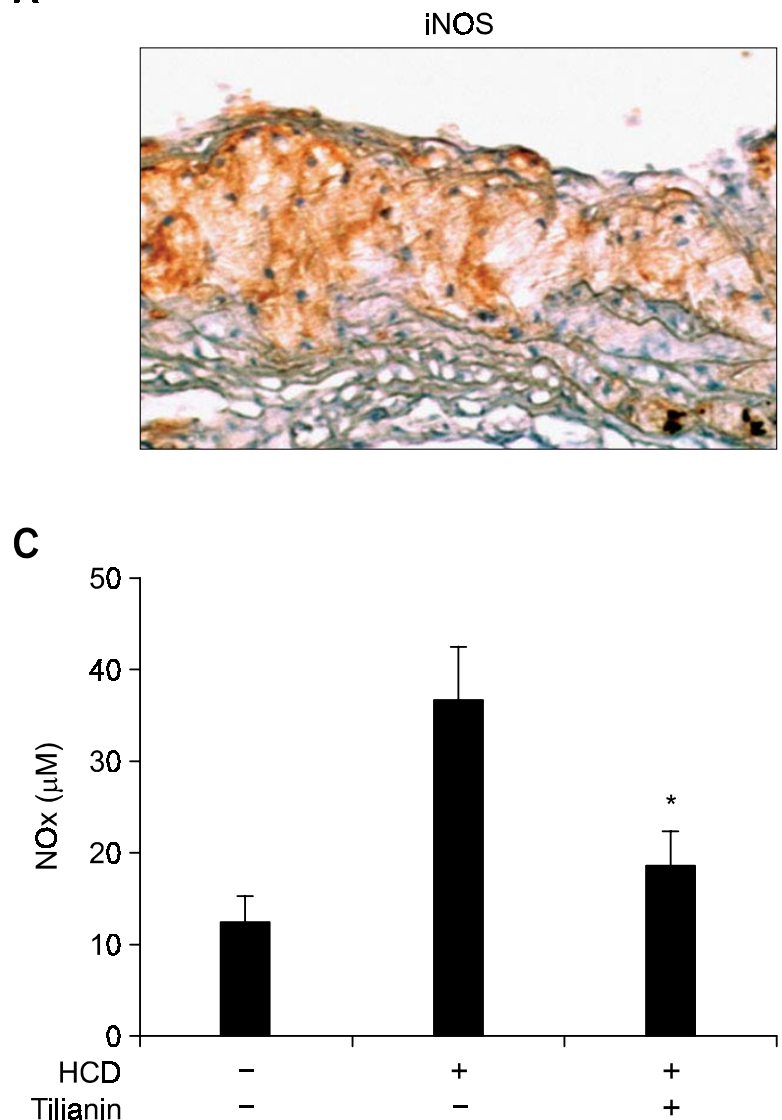

B

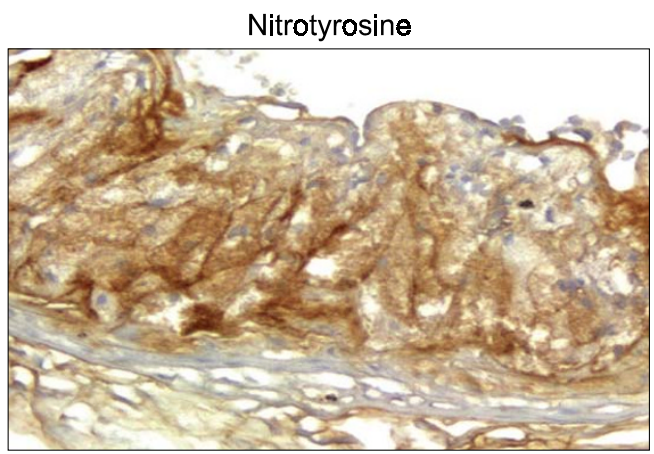

D

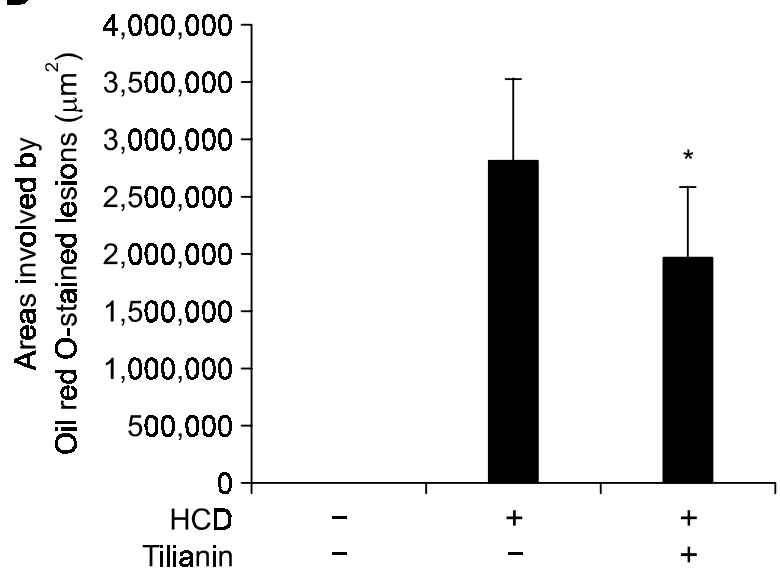

Figure 1. Localization of proatherogenic molecules in atherosclerotic lesions. iNOS $(A, \times 200)$ and nitrotyrosine $(B, \times 200)$ were detected by immunohistochemistry. Frozen sections of aortic segment were stained with polyclonal antibody for each molecule and detected using an ABC method. Section was then counterstained with Harris' hematoxylin. Control staining without primary antibodies did not show any significant staining in atherosclerotic lesion (data not shown). (C) Effect of tilianin on the plasma NO level in HCD-fed Ldlr-/- mice. The plasma was obtained from mice fed normal diet only, HCD only, and HCD supplemented with tilianin $(0.01 \%$ wt/wt diet). (D) Oil red $\mathrm{O}$ stained aortic valve lesion areas were quantified by computer-associated morphometry. All results are shown as mean $\pm \mathrm{SD}$. * indicates $P<0.01$ compared with $\mathrm{HCD}$ only group. 
nuclei, and the collected nuclei was suspended in buffer B [20 mM HEPES (pH 7.5), $1.5 \mathrm{mM} \mathrm{MgCl}_{2}$, $0.42 \mathrm{M} \mathrm{NaCl}, 0.2 \mathrm{mM}$ EDTA, and $25 \%$ glycerol] and incubated on ice for $30 \mathrm{~min}$. Following centrifugation, the nuclear extracts in the supernatant were harvested and protein concentrations were determined by Bradford method (Bio-Rad Laboratories, Inc., CA). For Electrophoretic mobility shift assays, $5 \mu \mathrm{g}$ of nuclear protein was reacted with $\left[{ }^{32} \mathrm{P}\right]-\gamma \mathrm{ATP}$ labeled NF- $\mathrm{KB}$ oligonucleotide (Promega, WI) in presence of $1 \mu \mathrm{g}$ of poly (dl-dC) (Sigma). To check for specificity, antibody against the p65 subunit of NF- $\mathrm{BB}$ (Santa Cruz Biotechnology, CA) was added to the binding reaction. Nuclear extracts-oligonucleotide mixtures were then subjected to eletrophoresis on $5 \%$ nondenaturing polyacrylamide gels. Gels were then dried and visualized by autoradiography.

\section{Statistics}

The data are expressed as the mean $\pm S D$. Statistical significance was determined by Student's $t$ test.

\section{Results}

\section{Localization of iNOS, nitrotyrosine in atheromatous plaques}

We confirmed the iNOS expression in atheromatous plaque of Ldlr-/- mice fed HCD by immunohistochemistry using antibodies specific for mouse iNOS. Control staining without primary antibodies showed no staining in atherosclerotic lesion (data not shown). Localization of iNOS protein was prominent in the atheromatous thickened intima (Figure 1A). No immunoreactivity for nitrotyrosine was detected in normal aortic sinus area (data not shown). Nitrotyrosine, however, was easily detected in the corresponding lesion site in which prominent iNOS expression was detected (Figure 1B). These results indicate that iNOS expression in atheromatous plaques is associated with the formation of nitrotyrosine.

\section{Effects of tilianin on plasma levels of NO and lesion formation}

We next examined the effect of tilianin on the plasma level of NO. Ldlr-/- mice fed with HCD resulted in increased plasma level of $\mathrm{NO}_{x}$, a stable oxidized product of NO. In mice fed with HCD supplemented tilianin, however, the $\mathrm{NO}_{\mathrm{x}}$ level was significantly decreased by about $50 \%$ (Figure 1C). In correspondence to the lowered NOx level, the

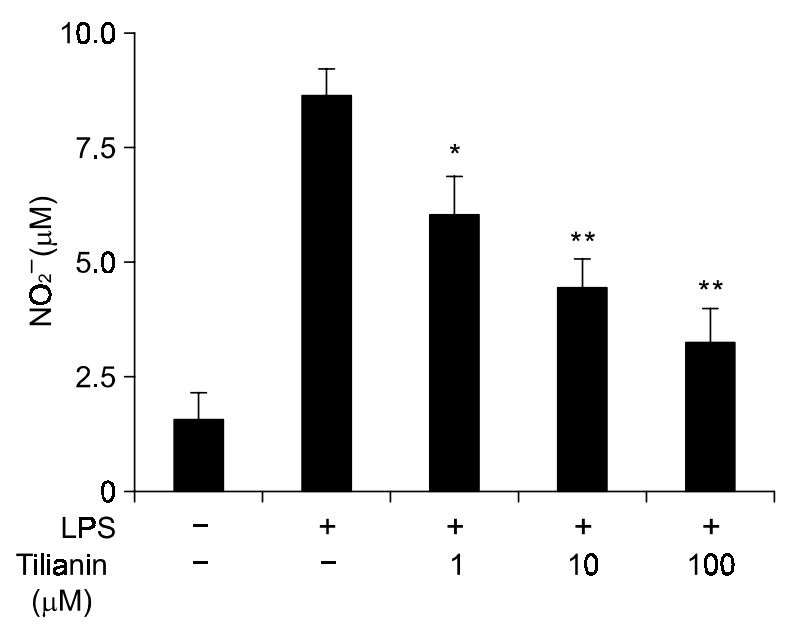

Figure 2. Effect of tilianin on NO production in LPS $(2 \mu \mathrm{g} / \mathrm{ml})$ activated peritoneal macrophage. Inhibition of NO production in LPS activated peritoneal macrophage by tilianin. The primary peritoneal macrophages from Ldlr-/- mice were incubated with tilianin $(1,10,100 \mu \mathrm{M})$ for $2 \mathrm{~h}$ and then activated with LPS $(2 \mu \mathrm{g} / \mathrm{ml})$ for $18 \mathrm{~h}$. The results are expressed as mean \pm SD $(n=3)$. NO production was measured by Griess reaction. ${ }^{*},{ }^{* *}$ indicates $P<0.05$ and $P<0.01$ compared with $\mathrm{HCD}$ only group, respectively.

lesions induced by HCD were decreased by the treatment of tilianin, similar to our previous study (Nam et al., 2005) (Figure 1D).

Tilianin inhibits the NO production and iNOS expression under in vitro inflammatory condition

Since tilianin has anti-atherogenic effect, the decrease of serum NO level may reflect the consequence of the reduction of inflammatory cell accumulation in the lesion area. Thus, we investigate whether tilianin directly affect the production of NO and the expression of iNOS gene in peritoneal macrophages stimulated with LPS $(2 \mu \mathrm{g} / \mathrm{ml})$ in the presence of various concentrations of tilianin. LPSinduced increased NO production was decreased in concentration-dependent manner by tilianin (Figure 2). Moreover, increased expression of iNOS mRNA and protein in macrophages stimulated by LPS was markedly inhibited in a dose-dependent manner by the treatment of tilianin (Figure $3 \mathrm{~A}, \mathrm{~B}$ and $\mathrm{C}$, respectively). These results suggest that tilianin inhibits effectively the NO production by modulating iNOS expression under in vitro inflammatory condition.

\section{Tilianin inhibits iNOS promoter activity and NF- $\kappa$ B activation}

We examined whether tilianin suppressed iNOS promoter activity. Transient transfection in the mouse 
A

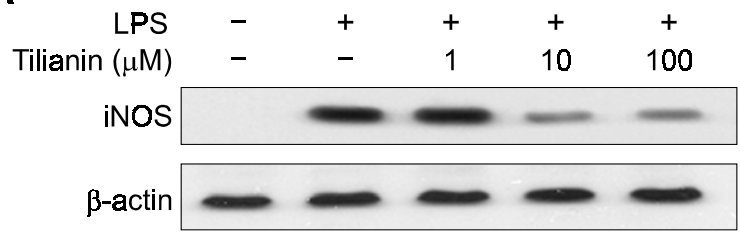

B

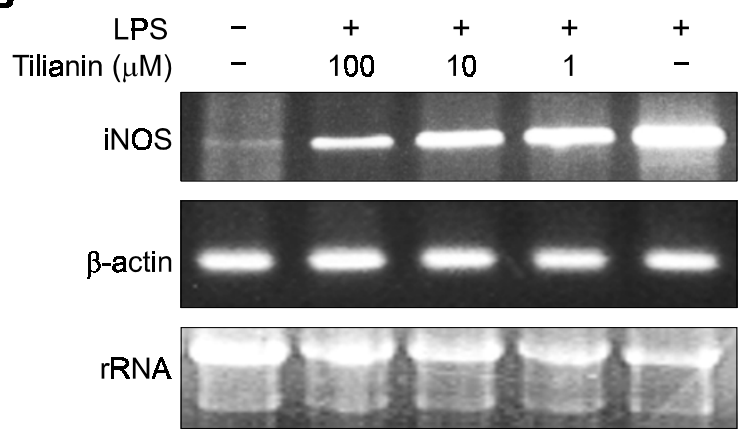

C

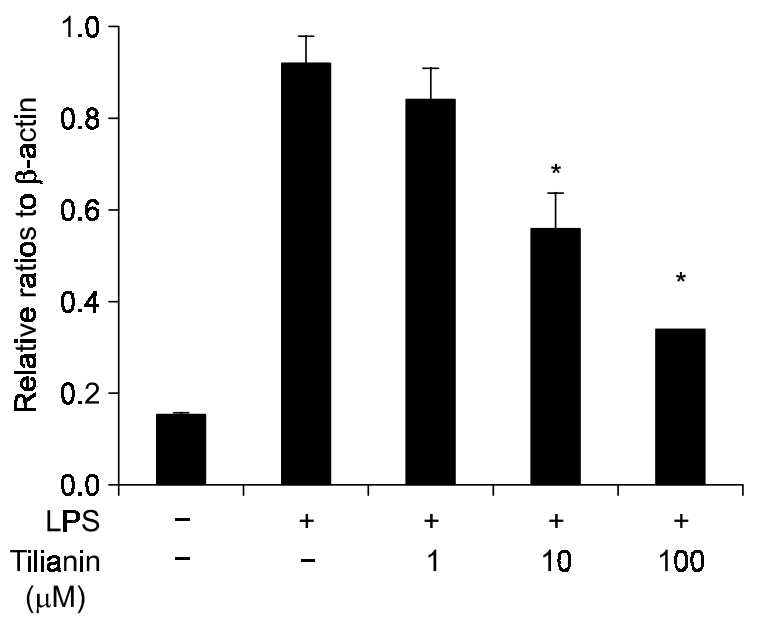

Figure 3. Effect of tilianin on iNOS expression in LPS $(2 \mu \mathrm{g} / \mathrm{ml})$ activated peritoneal macrophage. (A) Inhibition of iNOS expression in peritoneal macrophage by tilianin. iNOS expression was determined by immunoblot analysis as described in Methods. (B) Determination of iNOS mRNA expression levels by semi-quantitative RT-PCR. (C) A graph showing relative iNOS mRNA level in B. The primary peritoneal macrophages from Ldlr-/- mice were incubated with tilianin $(1,10,100 \mu \mathrm{M})$ for $2 \mathrm{~h}$ and then activated with LPS $(2 \mu \mathrm{g} / \mathrm{ml})$ for $18 \mathrm{~h}$. The results are expressed as mean \pm SD $(n=3)$. NO production was measured by Griess reaction. * indicates $P<0.05$ compared with HCD only group, respectively.

macrophage cell line RAW264.7 cells was performed with a murine iNOS promoter construct (piNOSLuc) by lipofection. Treatment of the transfected cells with LPS and IFN- $\gamma$ resulted in a 15 -fold increase in luciferase activity. This increase was suppressed in a dose-dependent manner by increasing concentrations of tilianin (Figure 4A). The expression of iNOS has been reported to be regulated by NF-kB activation (Barnes and Karin, 1997). Therefore, it is possible that tilianin inhibits NO production in peritoneal macrophages by inhibition of NF-KB activation. To investigate the roles of tilianin in NF- $\mathrm{KB}$ dependent gene transcription, we conducted a transient transfection assay using a DNA construct containing SV40 promoter, 5 repeats of the consensus NF-kB binding sequence, and the luciferase reporter gene. Stimulation of the transfectant with LPS resulted in an approximate 45 -fold increase in luciferase activity, and this increase was inhibited dose-dependently by tilianin treatment (Figure 4B). These results indicate that tilianin inhibits NF- $\mathrm{KB}$ activation and may subsequently suppress iNOS and inflammatory cytokines of which expressions are NF-kB-dependent. Next, the effect of tilianin on NF-kB activation in peritoneal macrophages was evaluated by electrophoretic mobility shift assay. The nuclear extract from LPS-stimulated primary macrophages showed an increase in NF-kBDNA binding activity, whereas any protein-oligonucleotide complex was not detected in unstimulated control cells. The binding activity was suppressed in a dose-dependent manner by the addition of tilianin (Figure 4C). Specificity of the DNAprotein interaction for NF-kB was demonstrated by the presence of antibody for the p65 subunit of $\mathrm{NF}-\kappa \mathrm{B}$ in the complex using a supershift assay (Figure 4C).

\section{Discussion}

We investigated the effect of tilianin upon inducible nitric oxide production in vivo and in vitro. We demonstrated that tilianin reduced the level of nitric oxide in plasma from LdIr-/- mice fed with HCD and that tilianin suppressed the expression of iNOS gene in peritoneal macrophages isolated from Ldlr-/- mice. This compound also inhibited the transcriptional activation of iNOS promoter that has NF- $\mathrm{KB}$ binding element. Thus, these results provide the first evidence that tilianin inhibit iNOS expression and NO production, suggesting a possible anti-atherogenic mechanism of tilianin in hyperlipidemic model mice.

Nitric oxide produced by iNOS inhibits the proliferation and induces apoptosis in vascular endothelial cells (Cornwell et al., 1994; Fukuo et al., 1996). It also produces the powerful oxidant peroxynitrite $\left(\mathrm{ONOO}^{-}\right)$by interacting with the reactive oxygen superoxide (Beckman and Koppenol, 1996). Peroxynitrite has been strongly implicated as a 
A
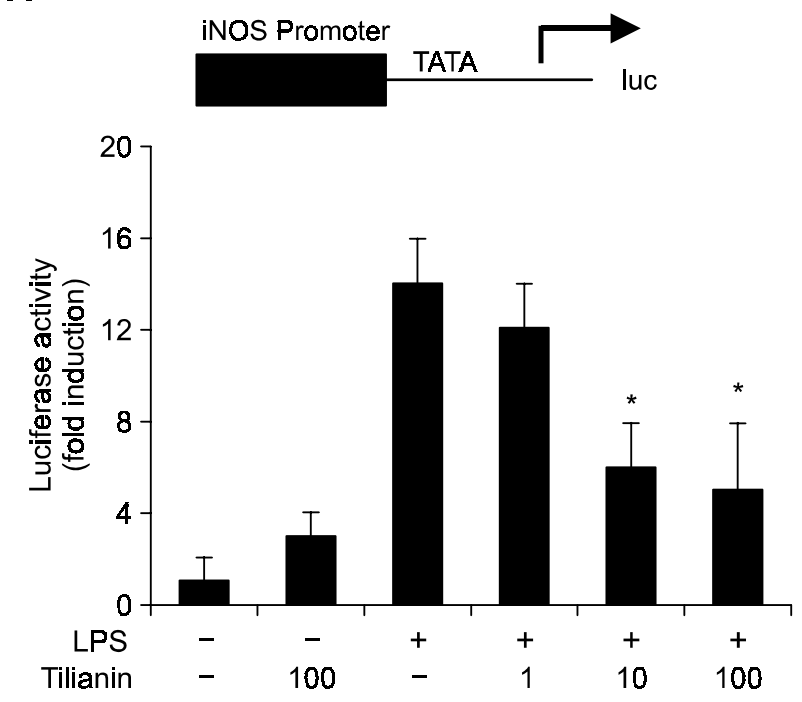

$(\mu \mathrm{M})$

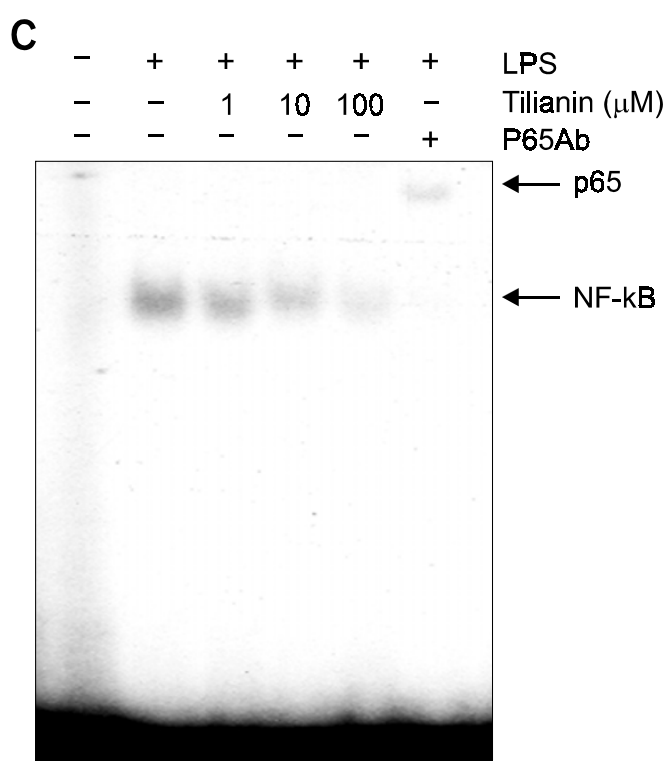

B
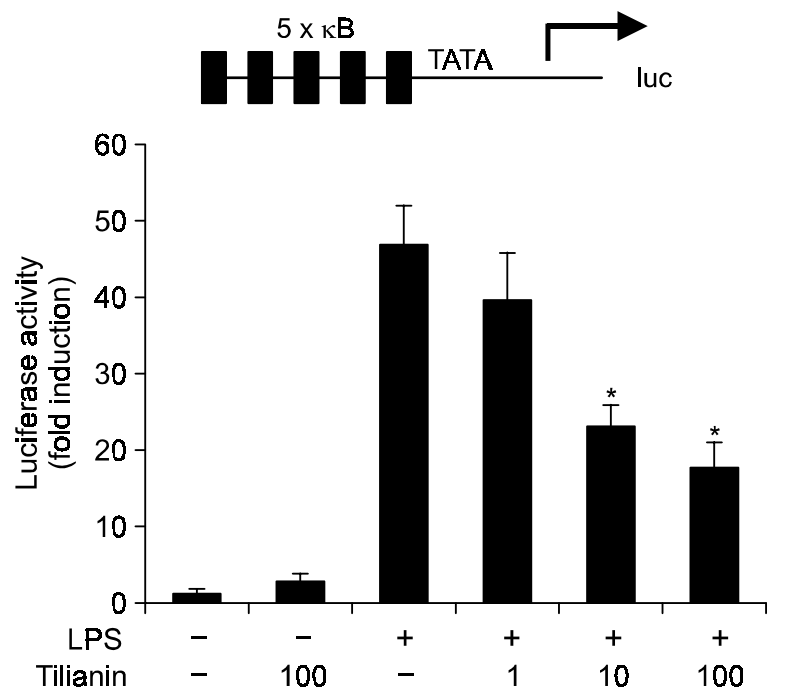

$(\mu \mathrm{M})$

Figure 4. Effect of tilianin on the activation of NF-KB and NF-KB-dependent promoter activity. (A) Inhibition of iNOS promoter activity and (B) NF-KB enhancer element activity by tilianin. pNF-kB-Luc plasmid and piNOS-Luc plasmid containing iNOS promoter were transfected to RAW264.7 cells. The control plasmid pCMVb $(1 \mu \mathrm{g})$ was co-transfected to monitor the transfection efficiency. After $20 \mathrm{~h}$ of transfection, cells were treated with LPS $(200 \mathrm{ng} / \mathrm{ml})$ in the presence of tilianin for $48 \mathrm{~h}$. Cells were harvested and luciferase activities were determined. The experiments were performed three times, and standard deviations are shown. (C) Inhibition of NF-KB activation was analyzed by electrophretic mobility shift assay (EMSA). Macrophages were pretreated with the indicated concentrations of tilianin for $2 \mathrm{~h}$, and stimulated with LPS (2 $\mu \mathrm{g} / \mathrm{ml}$ ) for $30 \mathrm{mim}$. For supershift assay, antibody against the p65 subunit of NF- $\mathrm{kB}$ (Santa Cruz Biotechnology) was added to the binding reaction. * indicates $P<0.01$ compared with the LPS only treated group.

cytotoxic effector molecule contributing to cellular damage and promoting the formation of atherosclerotic lesion (Wilcox et al., 1997). However, there are several conflicting papers regarding the effect of iNOS inhibition on atherosclerotic lesion formation using genetically engineered mice. When fed with normal diet, iNOS/ApoE double knockout mice did not have any different lesion compared to ApoE littermate controls (Knowles et al., 2000). Furthermore, iNOS knockout mice fed with normal diet have hypertension, a two fold increase in plasma cholesterol level, and aortic atherosclerotic lesion (Ihrig et al., 2001). On the contrary, when fed with atherogenic diet, the lesion size was decreased in iNOS/
ApoE double knockout mice compared to littermate ApoE-/- controls (Detmers et al., 2000; Kuhlencordt et al., 2001). These findings suggest that excessively elevated plasma lipid level induced by atherogenic diet discloses the proathergenic potential of iNOS. In the present study, we investigated the possibility that tilianin would prevent atherosclerosis induced by HCD. Our data showed that iNOS expression and nitrotyrosine formation were detected in the atheromatous lesion, and tilianin effectively reduced NO synthesis in vitro or in vivo, suggesting that the inhibitory effect of tilianin on the production of $\mathrm{NO}$ and peroxynitrite is plausible mechanism responsible for its antiatherogenic activity. 
We further demonstrated that iNOS expression was significantly lowered by treatment of tilianin. Promoter region of iNOS contains $N F-\kappa B$ binding sequence, and NF-KB activation is required for iNOS gene expression (Lowenstein et al., 1993). We examined the role of tilianin in iNOS expression and its promoter activity in vitro. Transient transfection with reporter genes with NF-kB binding elements to RAW264.7 cells showed clearly that tilianin inhibited significantly NF-KB-dependent iNOS expression, which is responsible for reduced NO production. In conclusion, tilianin significantly inhibit NO production and iNOS expression through the inhibition of NF- $\mathrm{KB}$ dependent transcription. Thus, the inhibition of NO production could be a novel possible mechanism of the anti-atherogenic potential of tilianin. And, it also implies that tilianin has potential as an anti-inflammatory agent.

\section{Acknowledgement}

This work was supported by grants from the Vascular System Research Center of the Korean Science and Engineering Foundation, Molecular Cellular Biodiscovery Research Group (2004-01587), and Korea Research Foundation Grant (KRF-20050828-1) funded by Korea Government.

\section{References}

Barnes PJ, Karin M. Nuclear factor-kappaB: a pivotal transcription factor in chronic inflammatory diseases. N Engl J Med 1997;336:1066-71

Beasley D, Schwartz JH, Brenner BM. Interleukin 1 induces prolonged L-arginine-dependent cyclic guanosine monophosphate and nitrite production in rat vascular smooth muscle cells. J Clin Invest 1991;87:602-8

Beckman JS, Beckman TW, Chen J, Marshall PA, Freeman BA. Apparent hydroxyl radical production by peroxynitrite: implications for endothelial injury from nitric oxide and superoxide. Proc Natl Acad Sci USA 1990;87:1620-4

Beckman JS, Koppenol WH. Nitric oxide, superoxide, and peroxynitrite: the good, the bad, and ugly. Am J Physiol 1996; 271:C1424-37

Beckmann JS, Ye YZ, Anderson PG, Chen J, Accavitti MA, Tarpey MM, White CR. Extensive nitration of protein tyrosines in human atherosclerosis detected by immunohistochemistry. Biol Chem Hoppe Seyler 1994;375:81-8

Behr-Roussel D, Rupin A, Simonet S, Bonhomme E, Coumailleau S, Cordi A, Serkiz B, Fabiani JN, Verbeuren TJ. Effect of chronic treatment with the inducible nitric oxide synthase inhibitor $\mathrm{N}$-iminoethyl-L-lysine or with $\mathrm{L}$-arginine on progression of coronary and aortic atherosclerosis in hypercholesterolemic rabbits. Circulation 2000;102:1033-8

Buttery LD, Springall DR, Chester AH, Evans TJ, Standfield EN, Parums DV, Yacoub MH, Polak JM. Inducible nitric oxide synthase is present within human atherosclerotic lesions and promotes the formation and activity of peroxynitrite. Lab Invest $1996 ; 75: 77-85$

Cornwell TL, Arnold E, Boerth NJ, Lincoln TM. Inhibition of smooth muscle cell growth by nitric oxide and activation of cAMP-dependent protein kinase by cGMP. Am J Physiol 1994;267:C1405-3

Detmers PA, Hernandez M, Mudgett J, Hassing H, Burton C Mundt S, Chun S, Fletcher D, Card DJ, Lisnock J, Weikel R, Bergstrom JD, Shevell DE, Hermanowski-Vosatka A, Sparrow CP, Chao YS, Rader DJ, Wright SD, Pure E. Deficiency in inducible nitric oxide synthase results in reduced atherosclerosis in apolipoprotein E-deficient mice. J Immunol 2000;165:3430-5

Esaki T, Hayashi T, Muto E, Yamada K, Kuzuya M, Iguchi A. Expression of inducible nitric oxide synthase in T lymphocytes and macrophages of cholesterol-fed rabbits. Atherosclerosis 1997;128:39-46

Fukuo K, Hata S, Suhara T, Nakahashi T, Shinto Y, Tsujimoto Y, Morimoto S, Ogihara T. Nitric oxide induces upregulation of Fas and apoptosis in vascular smooth muscle. Hypertension 1996;27:823-6

Gross SS, Jaffe EA, Levi R, Kilbourn RG. Cytokine-activated endothelial cells express an isotype of nitric oxide synthase which is tetrahydrobiopterin-dependent, calmodulin-independent and inhibited by arginine analogs with a rank-order of potency characteristic of activated macrophages. Biochem Biophys Res Commun 1991;178:823-9

Hibbs JB Jr, Taintor RR, Vavrin Z, Rachlin EM. Nitric oxide: a cytotoxic activated macrophage effector molecule. Biochem Biophys Res Commun 1988;57:87-94

Hong JJ, Choi JH, Oh SR, Lee HK, Park JH, Lee KY, Kim JJ, Jeong TS, Oh GT. Inhibition of cytokine-induced vascular cell adhesion molecule-1 expression; possible mechanism for anti-atherogenic effect of Agastache rugosa. FEBS Lett 2001; 495:142-7

Ihrig M, Dangler CA, Fox JG. Mice lacking inducible nitric oxide synthase develop spontaneous hypercholesterolaemia and aortic atheromas. Atherosclerosis 2001;156:103-7

Kanner J, Harel S, Granit R. Nitric oxide as an antioxidant. Arch Biochem Biophys 1991;289:130-6

Knowles JW, Reddick RL, Jennette JC, Shesely EG, Smithies $\mathrm{O}$, Maeda N. Enhanced atherosclerosis and kidney dysfunction in eNOS-/-Apoe-/- mice are ameliorated by enalapril treatment. J Clin Invest 2000;105:451-8

Kuhlencordt PJ, Chen J, Han F, Astern J, Huang PL. Genetic deficiency of inducible nitric oxide synthase reduces atherosclerosis and lowers plasma lipid peroxides in apolipoprotein E-knockout mice. Circulation 2001;103: 3099-104

Lowenstein CJ, Alley EW, Raval P, Snowman AM, Snyder SH, Russell SW, Murphy WJ. Macrophage nitric oxide synthase gene: two upstream regions mediate induction by interferon gamma and lipopolysaccharide. Proc Natl Acad Sci USA 1993;90:9730-4

Luoma JS, Stralin P, Marklund SL, Hiltunen TP, Sarkioja T, Yla-Herttuala S. Expression of extracellular SOD and iNOS in 
macrophages and smooth muscle cells in human and rabbit atherosclerotic lesions: colocalization with epitopes characteristic of oxidized LDL and peroxynitrite-modified proteins. Arterioscler Thromb Vasc Biol 1998;18:157-67

MacMicking J, Xie QW, Nathan C. Nitric oxide and macrophage function. Annu Rev Immunol 1997;15:323-50

Morita K, Ihnken K, Buckberg GD, Sherman MP, Young HH, Ignarro LJ. Role of controlled cardiac reoxygenation in reducing nitric oxide production and cardiac oxidant damage in cyanotic infantile hearts. J Clin Invest 1994;93:2658-66

Nam KW, Kim J, Hong JJ, Choi JH, Mar W, Cho MH, Kim YM, Oh SR, Lee HK, Nam KH, Oh GT. Inhibition of cytokine-induced $I_{\kappa} B$ kinase activation as a mechanism contributing to the anti-atherogenic activity of tilianin in hyperlipidemic mice. Atherosclerosis 2005;180:27-35

Paigen B, Morrow A, Holmes PA, Mitchell D, Williams RA.
Quantitative assessment of atherosclerotic lesions in mice. Atherosclerosis 1987;68:231-40

Schulz R, Nava E, Moncada S. Induction and potential biological relevance of a $\mathrm{Ca}(2+)$-independent nitric oxide synthase in the myocardium. Br J Pharmacol 1992;105:575-80

Sherman MP, Aeberhard EE, Wong VZ, Griscavage JM, Ignarro LJ. Pyrrolidine dithiocarbamate inhibits induction of nitric oxide synthase activity in rat alveolar macrophages. Biochem Biophys Res Commun 1993;191:1301-8

Wever RM, Luscher TF, Cosentino F, Rabelink TJ. Atherosclerosis and the two faces of endothelial nitric oxide synthase. Circulation 1998;97:108-112

Wilcox JN, Subramanian RR, Sundell CL, Tracey WR, Pollock JS, Harrison DG, Marsden PA. Expression of multiple isoforms of nitric oxide synthase in normal and atherosclerotic vessels. Arterioscler Thromb Vasc Biol 1997;17:2479-88 